\title{
Financial Inclusion and Economic Growth in WAEMU: A Multiscale Heterogeneity Panel Causality Approach
}

\author{
Grakolet Arnold Z. Gourène' ${ }^{1,2}$, Pierre Mendy ${ }^{2}$ \\ ${ }^{1}$ Laboratory of Research in Economics and Management, Jean Lorougnon Guédé University, Daloa, Côte d'Ivoire \\ ${ }^{2}$ Laboratory of Mathematics of Decision and Numerical Analysis, Cheikh Anta Diop University of Dakar, Fann, Dakar, Sénégal \\ Email: grakolet88@gmail.com, pierre.mendy@ucad.edu.sn
}

How to cite this paper: Gourène, G.A.Z. and Mendy, P. (2019) Financial Inclusion and Economic Growth in WAEMU: A Multiscale Heterogeneity Panel Causality Approach. Theoretical Economics Letters, 9, 477-488.

https://doi.org/10.4236/tel.2019.93033

Received: October 20, 2018

Accepted: March 9, 2019

Published: March 12, 2019

Copyright $\odot 2019$ by author(s) and Scientific Research Publishing Inc. This work is licensed under the Creative Commons Attribution International License (CC BY 4.0).

http://creativecommons.org/licenses/by/4.0/

(c) (i) Open Access

\begin{abstract}
This paper examines the causal relationship between Financial Inclusion and economic growth in the West African Economic and Monetary Union (WAEMU) from 2006 to 2015 . We combined the heterogeneity panel causality test proposed by [1] with the Maximal Overlap Discrete Wavelet Transform (MODWT) to analyze the bi-directional causality at different time scales. We used two Financial Inclusion indicators: the overall rate of demographic penetration of financial services (Financial Inclusion supply) and the overall rate of use of financial services (Financial Inclusion demand). Our results show that at scale 1 ( 2 - 4 years), there is no causality between economic growth and Financial Inclusion indicators. However, at scale 2 (4-8 years), we found a bi-directional causality between economic growth and Financial Inclusion. Policymakers should therefore promote reforms that are beneficial to financial inclusion, especially on the supply side, while making the levers for macroeconomic growth more efficient, which also seems to be a decisive factor in financial inclusion.
\end{abstract}

\section{Keywords}

Financial Inclusion, Economic Growth, Time Scales, Heterogeneity Panel Causality, MODWT

\section{Introduction}

In recent years, the Central Bank of West African States $\left(\mathrm{BCEAO}^{1}\right)$ has implemented several reforms to promote Financial Inclusion (FI) in WAEMU ${ }^{2}$. These ${ }^{1}$ Banque Centrale des Etats de l'Afrique de l'Ouest.

${ }^{2}$ West African Economic and Monetary Union. 
reforms focus on the establishment of a legal framework and financial infrastructures more adapted to the banking activity, the support to the decentralized financial sector and the implementation of action promoting access to financial services $^{3}[2]$.

These reforms had a positive effect on the use of financial services. Indeed, [3] has shown a recent expansion of Financial Inclusion through mobile money accounts in WAEMU countries, particularly in Ivory Coast and Mali. [2] found that about 21.9 million individuals now have a mobile phone account against 11 million in 2013 in WAEMU. We noticed an increase from 2.6 to 7.8 million bank accounts from 2006 to 2014 and from 366,000 in 2010 to 16 million in 2016 of electronic money coin. Last years, the demographic access and the supply of financial services have also increased to 18.4 points of services for 10,000 adults in 2014 against 0.9 points in 2006 and from 0 point of services of electronic currency issuer in 2009 to 24,300 in 2014 (see [4]). These studies show the positive repercussions of the measures taken by the BCEAO on Financial Inclusion within WAEMU. However, the Financial Inclusion despite this recent expansion in WAEMU is still weak relatively to other regions (see [5]).

Financial Inclusion can be defined as "the pursuit of making financial services accessible at affordable costs to all individuals and businesses, irrespective of net worth and size respectively"4. For the [6] Financial Inclusion is "the proportion of individuals and firms that use financial services".

According to the World Bank and the $\mathrm{AfDB}^{5}$, the access to essential financial services would enable populations to have better living conditions (health, investment in business, education...).

Several authors have highlighted the beneficial effects of Financial Inclusion on economic growth. However, macroeconomic studies remain low. Some works such as those of [7] have shown that Financial Inclusion had the potential to enhance economic growth and development. [8] has demonstrated that Financial Inclusion indicators had a positive impact on growth but had to be coupled with financial development. [9] has found that various dimensions of Financial Inclusion promoted economic growth.

In sub-Saharian African countries, several studies related to Financial Inclusion have been conducted. [10] stated that the joint impact of Financial Inclusion and mobile phone development on growth was stronger. [11] found a strong positive correlation between Financial Inclusion and economic growth in Kenya. [12] and [13] showed that the effects of Financial Inclusion on the economic growth of Nigeria are positive. The [14] argued that Financial Inclusion by lowering constraints to access credit generally boosted growth in African emerging and developing countries.

The purpose of this paper is to determine whether the measures taken in recent years to promote financial inclusion have indeed caused economic growth in WAEMU and vice versa. According to [15], Financial Inclusion can be de${ }^{3}$ Mobile money included. ${ }^{4}$ http://www.investopedia.com.

${ }^{5}$ African Development Bank. 
fined in 3 dimensions: access, use, and quality of financial services. Here we use two indicators as proxies for financial inclusion: the overall rate of demographic penetration of financial services and the overall rate of use of financial services ${ }^{6}$. These proxies serve to analyze the impact of financial inclusion from the point of view of supply and demand for financial products. The first indicator is used as proxy for access and quality to financial services and also represents the financial inclusion supply. The second one, as proxy for the use of financial services. It stands for the demand for financial inclusion as well. We want to see which of the policies favoring the supply or demand of financial services is conducive to a sustained economic growth and vice versa.

In our present paper, we propose a dynamic approach of analysis of the causality between Financial Inclusion and growth. The approach used here allows to analyze the evolution and the direction of causality over different time scales. We favor this approach for certain reasons. First of all, [8] supported the possibility of a reverse causation in this relationship between the variables in time.

Then, these data at different time scales make it possible to analyze economic relations more precisely (economic relations are far from being static) than to a single time scale using raw data. Several authors have confirmed the importance of taking into account different time scales in the analysis of the links between economic variables. [16] talked about the importance of taking into account the time scale for a more realistic analysis of the relationships between economic variables ${ }^{7}$. [17] asserted that the true economic relationships between variables are those found at the disaggregated level (data at different timescales) rather than at the usual aggregate level (raw data). According to these authors, aggregate data estimate an average of relationships across time scales that can mitigate the effect of each regressor on all timescales. There are also several authors such as [17] [18] [19] [20] who showed the empirical advantages of the analysis at different time scales ${ }^{8}$ on classical methods in the analysis of macroeconomic relations.

To study this relationship at different time scales, we have combined the wavelet methods and the panel causality test proposed by [1]. First, we have implemented the MODWT ${ }^{9}$ to get the data at different time scales. And then, we have applied the panel causality test at each time scale. The wavelet analysis allows to accurately choose and to analyze the time scale where we want to study the causality between variables. In addition, this methodology allows: Firstly, the analysis of non-stationary series dynamics (see [21]) which avoids the loss of information subject to the stationarisation of data and secondly this approach releases the hypothesis of co-integration of data of $\mathrm{ECM}^{10}$.

${ }^{6}$ Mobile Money Included

${ }^{7}$ Solow [16] says "I can easily imagine that there is a true macrodynamics, valid at every time scale... At short scales, I think something sort of Keynesian is a good approximation, and surely better than anything straight neoclassical. At very long scales, the interesting questions are best studied in a neoclassical framework... At the five to ten years time scale, we have to piece things together as best as we can, and look for a hybrid model that will do the job."

${ }^{8}$ Dynamic Analysis.

${ }^{9}$ Maximal Overlap Discrete Wavelet Transform.

${ }^{10}$ Error Correction Models. 
The contribution of this work is threefold. Firstly, this study seeks to fill the gap in the literature on the relationship between Financial Inclusion and economic growth in the WAEMU. Secondly, this study allows at different time scales, to investigate the dynamic causality between Financial Inclusion and growth. And thirdly, this study analyzes financial inclusion in terms of supply and demand for financial services simultaneously.

The rest of the study is structured as follows. Section 2 presents a brief review of the literature on Financial Inclusion and growth relationship. Section 3 provides the econometric methodology used to analyze the Financial Inclusion and growth causality. Section 4 examines the data and empirical results and Section 5 concludes.

\section{Literature Review}

The literature on the nexus between Financial Inclusion and economic growth from a macroeconomic point of view is recent and not very extensive. [7] have shown that Financial Inclusion could stimulate economic growth. They also argued that Financial Inclusion could create capital because of this strong positive correlation with the total factor productivity. They concluded that Financial Inclusion could increase the savings portfolio, the efficiency of intermediation of financial sector, foster entrepreneurship and thus economic growth. [8] have used macroeconometrics and microeconometrics methodologies to study the link between Financial Inclusion and GDP growth. The results showed that Financial Inclusion has a positive impact on GDP growth but must be combined with financial development. However, as more inclusion and financial development increase, the positive effect of inclusion on growth decreases. [9] using the Vector auto-regression (VAR) and the Granger causality, have shown that various dimensions of Financial Inclusion (banking penetration, availability, and usage of banking services) have positively impacted the economic growth. This author found a bi-directional causality between the geographical penetration of banking services and the economic development and a unidirectional causality between the number of deposits and the GDP.

In sub-Saharan African countries, [10] have addressed the question of whether Financial Inclusion was one of the channels through which the development of mobile telephony improved the economic growth. They have shown that mobile penetration had a positive impact on the economic growth by facilitating Financial Inclusion, and it has also consolidated the impact of Financial Inclusion on the economic growth. A greater penetration of mobile telephony increases access to deposits and loans. They have concluded that the joint impact of Financial Inclusion and mobile phone development on the growth was stronger. [11] has investigated the relationship between Financial Inclusion and economic growth in Kenya. She has found that the economic growth had a strong positive correlation with Financial Inclusion, especially the branch networks of the banking sector, mobile money accounts and the users. [12] studied the im- 
pacts of Financial Inclusion on the economic growth of Nigeria. He found out a significant positive relationship between financial inclusion and economic growth. Besides, the author showed that Financial Inclusion greatly influenced poverty reduction and financial intermediation through positively impacted Bank Branch Networks, loans to rural areas and small enterprises. [13] were interested in the impact of Financial Inclusion on growth. They discovered that Financial Inclusion positively impacted, both, the total factor of production and the capital per worker. Which ones have a positive effect on the final output of the economy. The [14] by using a micro-founded general equilibrium model, analyzed the impact of Financial Inclusion on growth in Africa. It brought to the fore that lowering both credit access constraints and participation costs to market for firms and companies could stimulate growth and productivity and reduce inequality. In WAEMU, it is clear that there is a gap in the literature. Studies on this subject within WAEMU are almost non-existent.

\section{Methodology}

In this section, we present the econometric methodology used to study the causality between Financial Inclusion and economic growth. First, we provide an overview of Maximum Overlap Discrete Wavelet Transform, and then, follows the panel causality test proposed by [1].

\subsection{Maximum Overlap Discrete Wavelet Transform (MODWT)}

We use the MODWT to implement the data at different time scales (see [21]). The MODWT localizes variations in the signal or time series in time and frequency simultaneously. The variability and the evolution over time can be captured by decomposing the time series at many timescales.

Let $X_{t}$, the data. The time series can be decomposed by a sequence of projections onto wavelet basis:

$$
\begin{array}{r}
s_{J, k}=\int X_{t} \Phi_{J, k}(t) \mathrm{d} t \\
d_{j, k}=\int X_{t} \psi_{j, k}(t) \mathrm{d} t
\end{array}
$$

where $j=1,2, \cdots, J$, the level of multiresolution and $J=\log _{2}(T)$; $\Phi$, the father wavelet and $\Psi$, the mother wavelet. $s_{J, k}$, the smooth wavelet coefficient (long run movements) provides a smooth or overall pattern of the original signal and $d_{j, k}$, the wavelet detail coefficient (short run movements) capture local fluctuations in each scale over the entire period of a time series. $\Phi_{J, k}$ and $\psi_{j, k}$ are scaling and translation obtained from $\Phi$ and $\Psi$ and are defined as follow

$$
\begin{aligned}
& \Phi_{J, k}(t)=2^{-j / 2} \Phi\left(2^{-j} t-k\right)=2^{-j / 2} \Phi\left(\frac{t-2^{j} k}{2^{j}}\right) \\
& \Psi_{J, k}(t)=2^{-j / 2} \Psi\left(2^{-j} t-k\right)=2^{-j / 2} \Psi\left(\frac{t-2^{j} k}{2^{j}}\right)
\end{aligned}
$$

For the decomposition, we use Daubechies least asymmetric (LA) wavelet fil- 
ter of length 8 because it is one of the best and most used in wavelets theory.

The decomposition of the series by the MODWT is usually implemented by the Pyramidal Algorithm (see [22]). The multiresolution analysis of the $X_{t}$ using the MODWT can be written as follows

$$
X_{t}=\sum_{j=1}^{J} d_{j, k}+s_{J, k},
$$

\subsection{Panel Heterogeneity Causality Test}

We apply to the data at different time scales, the heterogeneity panel causality test introduced by $[1]^{11}$. This test is an extension to panel data version of the [23] causality test for time series. The underlying regression is written as follows

$$
y_{i, t}=\alpha_{i}+\sum_{k=1}^{K} \beta_{i k} y_{i, t-k}+\sum_{k=1}^{K} \gamma_{i k} x_{i, t-k}+\epsilon_{i, t}
$$

where $x_{i, t}$ and $y_{i, t}$ are the observations of two stationary variables for individual $i$ in period $t$ and $\alpha_{i}$ are the fixed effects. Coefficients are allowed to differ across individuals but are assumed time-invariant. The maximal lag order $K$ is assumed to be identical for all individuals and the panel must be balanced.

As in [23], the procedure to determine the existence of causality is to test for significant effects of past values of $x$ on the present value of $y$. The null hypothesis is therefore defined as

$$
H_{0}: \gamma_{i 1}=\gamma_{i 2}=\cdots=\gamma_{i k}=0, \forall i=1, \cdots, N
$$

which corresponds to the absence of causality for all individuals in the panel. The test assumes there can be causality for some individuals but not necessarily for all. The alternative hypothesis is thus written

$$
\begin{aligned}
H_{1}: \gamma_{i 1} & =\gamma_{i 2}=\cdots=\gamma_{i k}=0, \forall i=1, \cdots, N_{1} \\
\gamma_{i 1} & \neq 0 \text { or } \gamma_{i 2} \neq 0 \text { or } \cdots \text { or } \gamma_{i k} \neq 0, \forall i=1, \cdots, N_{1}+1, \cdots, N
\end{aligned}
$$

where $N_{1} \in[0 ; N-1]$ is unknown. If $N_{1}=0$, there is causality for all individuals in the panel. $N_{1}$ is strictly smaller than $N$, otherwise there is no causality for all individuals and $H_{1}$ reduces to $H_{0}$. Against this backdrop, $\mathrm{DH}$ propose the following procedure: run the $N$ individual regressions implicitly enclosed in (6), perform F-tests of the $K$ linear hypotheses $\gamma_{i 1}=\gamma_{i 2}=\cdots=\gamma_{i k}=0$ to retrieve $W_{i}$, and finally we compute $\bar{W}$ as the average of the $N$ individual Wald statistics

$$
\bar{W}=\frac{1}{N} \sum_{k=1}^{K} W_{i}
$$

where $W_{i}$ is the standard adjusted Wald statistic for individual $i$ observed during $T$ periods. We emphasize that the test is designed to detect causality at the panel-level, and rejecting $H_{0}$ does not exclude that there is no causality for some individuals. Using Monte Carlo simulations, $\mathrm{DH}$ show that $\bar{W}$ is asymptotically well-behaved and can genuinely be used to investigate panel causality. Un${ }^{11} \mathrm{DH}$. 
der the assumption that Wald statistics $W_{i}$ are independently and identically distributed across individuals, it can be shown that the standardized statistic $\bar{Z}$ when $T \rightarrow \infty$ and then $N \rightarrow \infty$ (sometimes interpreted as $T$ should be large relative to $N$ ) follows a standard normal distribution

$$
\bar{Z}=\sqrt{\frac{N}{2 K}} \times(\bar{W}-K) \rightarrow \mathcal{N}(0,1)
$$

Also, for a fixed $T$ dimension with $T>5+3 K$, the approximated standardized statistic $\tilde{Z}$ follows a standard normal distribution

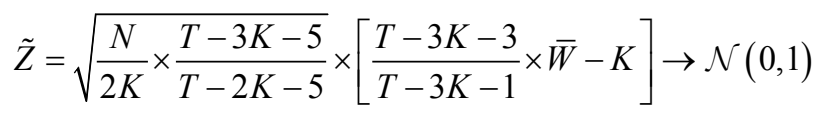

The testing procedure of the null hypothesis in (7) is finally based on $\bar{Z}$ and $\tilde{Z}$. If these are larger than the corresponding normal critical values, then one should reject $H_{0}$ and conclude that there is Granger causality. For large $N$ and $T$ panel datasets, $\bar{Z}$ can be reasonably considered. For large $N$ but relatively small $T$ dataset, $\tilde{Z}$ should be favored. Using Monte Carlo simulations, DH have shown that the test exhibits very good finite sample properties, even with both $T$ and $N$ small.

\section{Data and Empirical Results}

The dataset consists of a cross-country observation\ from 8 countries from WAEMU countries over the 2006-2015 period. We use annual data. The dataset has been obtained from the World Bank and Central Bank of West African States (BCEAO) databases. We use two proxies of Financial Inclusion: the overall rate of demographic penetration of financial services (DemoF), representing the access and the available supply of financial services and the overall rate of use of financial services (UseF) standing for the demand and use of financial services. As economic growth proxy, we work with GDP per capita growth (GDPg). The choice of this period of study is the consequence of a constraint on the data. Some descriptive statistics are reported in Table 1.

Firstly, we compute the wavelet coefficients using the MODWT to obtain the data at different time scales. For the decomposition, we use Daubechies Least Asymmetric (LA) wavelet filter of length $8^{12}$ (see [24]). The maximum number of scales or decompositions allowed is $\log _{2}(T)^{13}$ where $T$ is the number of observations. However, the wavelet coefficients become too small at large scales, then we have decided to stop to 2 decompositions or scales with 2 wavelet details and 1 smooth wavelet coefficient (long run dynamic or trend). Secondly, we apply three panel unit root tests at each scales (see Table 2). In case where the three tests contradict, the decision rule is a simple majority rule. The analysis of Table $2\left(\mathrm{MW}^{14}\right.$, IPS ${ }^{15}$, CIPS ${ }^{16}$ panel stationarity tests) shows that for the $D_{1}$ and ${ }^{12}$ One of the best wavelets filters used in the theory ([21]).

${ }^{13} \log _{2}(10)=3.3219$.

${ }^{14}$ Maddala and $\mathrm{Wu}$.

${ }^{15} \mathrm{Im}$, Pesaran and Shin.

${ }^{16}$ Cross-sectionally augmented IPS. 
Table 1. Descriptive statistics of variables from 2006 to 2015.

\begin{tabular}{|c|c|c|c|c|c|c|}
\hline Country & Variable & Observations & Mean & Standard Deviation & Minimum & Maximum \\
\hline \multirow[t]{3}{*}{ Benin } & DemoF & 10 & 4.335 & 5.9941 & 1.23 & 20.51 \\
\hline & UseF & 10 & 53.022 & 14.6982 & 34.63 & 80.79 \\
\hline & GDPg & 10 & 1.3752 & 1.8181 & -0.7088 & 4.2434 \\
\hline \multirow[t]{3}{*}{ Burkina-Faso } & DemoF & 10 & 4.716 & 6.3589 & 0.86 & 18.47 \\
\hline & UseF & 10 & 28.517 & 13.17174 & 10.54 & 53.19 \\
\hline & GDPg & 10 & 2.3454 & 1.8183 & -0.2054 & 5.2210 \\
\hline \multirow[t]{3}{*}{ Ivory Coast } & DemoF & 10 & 5.578 & 7.8365 & 0.38 & 23.03 \\
\hline & UseF & 10 & 37.635 & 24.2202 & 12.96 & 74.02 \\
\hline & GDPg & 10 & 2.0329 & 4.5305 & -6.6476 & 8.0017 \\
\hline \multirow[t]{3}{*}{ Guinea-Bissau } & DemoF & 10 & 0.737 & 0.4878 & 0.21 & 1.58 \\
\hline & UseF & 10 & 5.834 & 3.8490 & 1.2 & 13.94 \\
\hline & GDPg & 10 & 0.6820 & 2.7963 & -4.3148 & 6.5754 \\
\hline \multirow[t]{3}{*}{ Mali } & DemoF & 10 & 7.88 & 12.0920 & 1.25 & 37.49 \\
\hline & UseF & 10 & 33.652 & 18.9608 & 19.32 & 73.4 \\
\hline & GDPg & 10 & 0.8861 & 2.1193 & -3.7211 & 3.9826 \\
\hline \multirow[t]{3}{*}{ Niger } & DemoF & 10 & 8.997 & 13.4988 & 0.31 & 37.34 \\
\hline & UseF & 10 & 9.902 & 7.8389 & 0.86 & 23.1 \\
\hline & GDPg & 10 & 1.6940 & 3.5819 & -4.3880 & 7.6076 \\
\hline \multirow[t]{3}{*}{ Senegal } & DemoF & 10 & 11.217 & 14.3276 & 1.22 & 40.45 \\
\hline & UseF & 10 & 41.734 & 19.4756 & 21.85 & 76.3 \\
\hline & GDPg & 10 & 0.8863 & 1.3295 & -1.1819 & 3.4216 \\
\hline \multirow[t]{3}{*}{ Togo } & DemoF & 10 & 2.94 & 2.1022 & 1.43 & 8.44 \\
\hline & UseF & 10 & 50.361 & 19.6618 & 28.09 & 92.32 \\
\hline & GDPg & 10 & 1.36401 & 1.20776 & -0.5021 & 3.1481 \\
\hline
\end{tabular}

Table 2. Panel unit roots test of variables at different time scales.

\begin{tabular}{cccc}
\hline Variables & MW & IPS & CIPS \\
\hline Scale 1 $\left(D_{1}\right)$ & & & \\
DemoF & $54.994\left(0.000^{*}\right)$ & $-3.4318\left(0.0003^{\star}\right)$ & $-3.276\left(0.001^{\star}\right)$ \\
UseF & $248.144\left(0.000^{\star}\right)$ & $-4.9176\left(0.0000^{\star}\right)$ & $-4.421\left(0.000^{\star}\right)$ \\
GDPg & $268.071\left(0.000^{*}\right)$ & $-4.2589(0.0000)$ & $-1.790\left(0.037^{\star *}\right)$ \\
Scale 2 $\left(D_{2}\right)$ & & & \\
DemoF & $186.625\left(0.000^{*}\right)$ & $-3.4318\left(0.0003^{\star}\right)$ & $-3.266\left(0.001^{\star}\right)$ \\
UseF & $149.828\left(0.000^{*}\right)$ & $-4.2589\left(0.0000^{*}\right)$ & $-0.207(0.418)$ \\
GDPg & $394.928\left(0.000^{*}\right)$ & $-4.9176\left(0.0000^{\star}\right)$ & $-7.092\left(0.000^{*}\right)$ \\
Scale 3 $\left(S_{2}\right)$ & & & $-0.677(0.249)$ \\
DemoF & $0.000(1.000)$ & $2.7776(0.9973)$ & $-1.319\left(0.094^{* *}\right)$ \\
UseF & $0.000(1.000)$ & $2.5532(0.9947)$ & $-1.599\left(0.055^{* * *}\right)$ \\
GDPg & $0.000(1.000)$ & $2.0916(0.9818)$ & \\
\hline
\end{tabular}

Note: Numbers in the parenthesis show the p-values. ${ }^{*}$ Significant at the $1 \%$ level. ${ }^{*}$ Significant at the $5 \%$

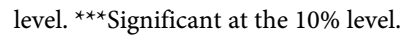


$D_{2}$ scales, the panel unit root hypothesis is rejected while for the $S_{2}$ scale it is not rejected. We cannot, therefore, use the $S_{2}$ scale in the analysis in view of the stationarity hypothesis of the VAR models.

Finally, we apply the DH panel causality test at $D_{1}$ and $D_{2}$ scales. Given the number of data, the optimal number of lags allowed by the DH panel causality test is $1^{17}$. Owing to the small size of our sample, the Ztilde test statistic is the most suitable (see Methodology Section) for the analysis of the results.

The test results in Table 3 indicate that at scale 1 ( $2-4$ years), there is no causality between the economic growth and the two indicators of Financial Inclusion. However, it should be noted that the Zbar statistic indicates that the economic growth causes the overall rate of growth of demographic services. In view of its contradictory results, the conclusions obtained from the Ztilde statistic, which is the most adapted to our study, must for reasons of robustness be taken with precautions at this scale. At scale 2 ( $4-8$ years), the causality is present and even bi-directional. The overall rate of demographic penetration of financial services (supply) and the overall rate of use of financial services (demand) cause GDP growth and vice versa. The analysis of the statistic tests Ztilde at scale 2 (4- 8 years) provides further information. Firstly, we have found out that economic growth causes more Financial Inclusion than the latter one does for economic growth. Indeed, a strong growth implies a greater income and therefore can lead to investments in financial infrastructures more ecient in order to sustain this growth. These investments consequently trigger an increase in the supply and quality of available financial services and thus make them more accessible to the population (geographical penetration). In addition, a rise in income implies a rise in the demand for financial services and therefore increases their use. Secondly, the use of financial services (demand) causes more economic growth than their demographic penetration. That can be explained by the fact that an increase in the use of financial services drives GDP per capita growth.

Table 3. DH panel causality at different times scales.

\begin{tabular}{cccccc}
\hline Scale $1\left(D_{1}: 2-4\right.$ years $)$ & Lag & Wbar & Zbar & Ztilde & HO \\
\hline DemoF $\rightarrow$ GDPg & 1 & 0.3413 & $-1.3174(0.1877)$ & $-0.9771(0.3285)$ & DemoF does not homogeneously cause GDPg \\
GDPg $\rightarrow$ DemoF & 1 & 2.0350 & $2.0701\left(0.0384^{* *}\right)$ & $0.4512(0.6519)$ & GDPg does not homogeneously cause DemoF \\
UseF $\rightarrow$ GDPg & 1 & 0.9061 & $-0.1879(0.8510)$ & $-0.5009(0.6165)$ & UseF does not homogeneously cause GDPg \\
GDPg $\rightarrow$ UseF & 1 & 1.4912 & $0.9825(0.3259)$ & $-0.0074(0.9941)$ & GDPg does not homogeneously cause UseF \\
\hline Scale 2 $\left(D_{2}: 4-8\right.$ years $)$ & Lag & Wbar & Zbar & Ztilde & HO \\
\hline DemoF $\rightarrow$ GDPg & 1 & 9.8974 & $17.7948\left(0.0000^{*}\right)$ & $7.0813\left(0.0000^{*}\right)$ & DemoF does not homogeneously cause GDPg \\
GDPg $\rightarrow$ DemoF & 1 & 24.8333 & $47.6665\left(0.0000^{*}\right)$ & $19.6763\left(0.0000^{\star}\right)$ & GDPg does not homogeneously cause DemoF \\
UseF $\rightarrow$ GDPg & 1 & 15.1078 & $28.2155\left(0.0000^{*}\right)$ & $11.4751\left(0.0000^{*}\right)$ & UseF does not homogeneously cause GDPg \\
GDPg $\rightarrow$ UseF & 1 & 21.5901 & $41.1803\left(0.0000^{*}\right)$ & $16.9415\left(0.0000^{*}\right)$ & GDPg does not homogeneously cause UseF \\
\hline
\end{tabular}

Note: Numbers in the parenthesis show the p-values. ${ }^{\star}$ Significant at the $1 \%$ level. ${ }^{\star}$ Significant at the $5 \%$ level.

${ }^{17} T>5+3 K$, where $K$ is the lag number. 
Indeed, the use of financial services by the population gives them access to savings and credit that have a positive impact on investment. Beyond this, there is also the facilitation and securisation of financial transactions that can lead to an increase in the dynamics of the economy. Finally, we could notice that economic growth triggers more geographic penetration of financial services than their use. Indeed, the populations, despite a rise in their income due to the economic growth, may decide personally not to use available financial services. This might be the consequence of this lower impact of economic growth on the use of financial services.

\section{Conclusions}

This study has examined the causal relationship between Financial Inclusion and economic growth using WAEMU panel data from 2006 to 2015 . We used the GDP per capita growth as the proxy of economic growth and two indicators as proxies of the Financial Inclusion: the overall rate of demographic penetration of financial services and the overall rate of use of financial services. We combined MODWT and panel causality test from [1] to analyze this relationship.

The findings reveal that the causal relationship between the economic growth and the Financial Inclusion depends on the time scale. At scale 1 (2 - 4 years), there is no causality but at scale 2 ( $4-8$ years), there is a bi-directional causality between the economic growth and the Financial Inclusion. We have also found that the use of financial services (demand) causes more economic growth than the demographic penetration of financial services (supply). But in the other sense, the economic growth causes more demographic penetration of financial services (supply) than the use of financial services (demand). The results are almost similar to those of [9]. There is no causality between the Financial Inclusion and the economic growth at short run but at medium or long run, there is a bi-directional causality. We can conclude that the financial inclusion measures implemented have actually stimulated WAEMU's growth in the long run and vice versa. These results show that, for a stronger inclusive growth, economic policies favoring the use or demand for services (lower borrowing rates, higher interest rates creditors, specialization of banks in the mobile money sector) in the first instance must be adopted. This will then lead to a sustained growth, which will promote the development or supply of financial products and so on.

The results from this study are relevant for policymakers. They could improve the Financial Inclusion and macroeconomic growth simultaneously to reach an inclusive and sustainable growth. Firstly, policymakers should continue to encourage and even intensify policies and reforms favoring the demand for financial services. This would stimulate the economic growth by increasing savings and therefore investments. At the same time, they should strengthen and liberalize the investment regulatory framework and create an environment conducive to exports by facilitating administrative procedures and fighting against corruption. All these measures will promote the economic growth which in turn 
will increase the supply of available financial services.

In short, policymakers and financial authorities should, while promoting financial inclusion, simultaneously put in place policies that simulate macroeconomic growth in order to have a stronger positive impact on both sides.

\section{Acknowledgements}

We thank the Editor and the referee for their comments.

\section{Conflicts of Interest}

The authors declare no conflicts of interest regarding the publication of this paper.

\section{References}

[1] Dumitrescu, E.I. and Hurlin, C. (2012) Testing for Granger Non-Causality in Heterogeneous Panels. Economic Modelling, 29, 1450-1460. https://doi.org/10.1016/j.econmod.2012.02.014

[2] BCEAO (2017) Stratégie régional d'inclusion financière dans l'UEMOA. Note d'Information N2/2017.

[3] Demirguc-Kunt, A., Klapper, L.F., Singer, D. and Van Oudheusden, P. (2015) The Global Findex Database 2014: Measuring Financial Inclusion around the World.

[4] BCEAO (2016) Conference régionale de haut niveau sur la finance pour tous: promouvoir l'inclusion financière en Afrique de l'ouest, Session 1: inclusion financière et reduction de la pauvrété: une vue d'ensemble, Sous thème 3: Inclusion financière dans l'UEMOA: état des lieux et stratégie de promotion.

[5] Mlachila, M., Cui, L., Jidoud, A., Newiak, M., Radzewicz-Bak, B., Takebe, M., Ye, Y. and Zhang, J. (2016) Financial Development in Sub-Saharan Africa Promoting Inclusive and Sustainable Growth. International Monetary Fund, African Department.

[6] World Bank (2014) Global Financial Development Report 2014: Financial Inclusion. World Bank, Washington DC. License: Creative Commons Attribution CC BY 3.0 .

[7] Hariharan, G. and Marktanner, M. (2012) The Growth Potential from Financial Inclusion. ICA Institute and Kennesaw State University.

[8] Sahay, R., Cihak, M., N’Diaye, P., Barajas, A., Mitra, S., Kyobe, A. and Yousefi, S.R. (2015) Financial Inclusion: Can It Meet Multiple Macroeconomic Goals? International Monetary Fund (No. 15/17).

[9] Sharma, D. (2016) Nexus between Financial Inclusion and Economic Growth: Evidence from the Emerging Indian Economy. Journal of Financial Economic Policy, 8, 13-36. https://doi.org/10.1108/JFEP-01-2015-0004

[10] Kpodar, K. and Andrianaivo, M. (2011) ICT, Financial Inclusion, and Growth Evidence from African Countries. IMF Working Paper No. 11/73.

[11] Oruo, J. (2013) The Relationship between Financial Inclusion and GDP Growth in Kenya. Department of Finance and Accounting School of Business, University of Nairobi.

[12] Onaolapo, A.R. (2015) Effects of Financial Inclusion on the Economic Growth of Nigeria (1982-2012). International Journal of Business and Management Review, 3, 11-28. 
[13] Babajide, A.A., Adegboye, F.B. and Omankhanlen, A.E. (2015) Financial Inclusion and Economic Growth in Nigeria. International Journal of Economics and Financial Issues, 5, 629-637.

[14] Outlook, Regional Economic (2015) Sub-Saharan Africa: Dealing with the Gathering Clouds. International Monetary Fund.

[15] Triki, T. and Faye, I. (2013) Financial Inclusion in Africa. African Development Bank.

[16] Solow, R.M. (2000) Towards a Macroeconomics of the Medium Run. Journal of Economic Perspectives, 14, 151-158. https://doi.org/10.1257/jep.14.1.151

[17] Gallegati, M., Gallegati, M., Ramsey, J.B. and Semmler, W. (2014) Does Productivity Affect Unemployment? A Time-Frequency Analysis for the US. In: Wavelet Applications in Economics and Finance, Springer International Publishing, Berlin, 23-46. https://doi.org/10.1007/978-3-319-07061-2_2

[18] Gallegati, M., Gallegati, M., Ramsey, J.B. and Semmler, W. (2011) The US Wage Phillips Curve across Frequencies and over Time. Oxford Bulletin of Economics and Statistics, 73, 489-508. https://doi.org/10.1111/j.1468-0084.2010.00624.x

[19] Aguiar-Conraria, L. and Soares, M.J. (2011) Business Cycle Synchronization and the Euro: A Wavelet Analysis. Journal of Macroeconomics, 33, 477-489. https://doi.org/10.1016/j.jmacro.2011.02.005

[20] Crowley, P.M. and Hallett, A.H. (2014) The Great Moderation under the Microscope: Decomposition of Macroeconomic Cycles in US and UK Aggregate Demand. In: Wavelet Applications in Economics and Finance, Springer International Publishing, Berlin, 47-71. https://doi.org/10.1007/978-3-319-07061-2_3

[21] Percival, D.B. and Walden, A.T. (2000) Wavelet Methods for Time Series Analysis. Cambridge Series in Statistical and Probabilistic Mathematics. https://doi.org/10.1017/CBO9780511841040

[22] Mallat, S. (1999) A Wavelet Tour of Signal Processing. Academic Press, Cambridge.

[23] Granger, C.W. (1969) Investigating Causal Relations by Econometric Models and Cross-Spectral Methods. Econometrica: Journal of the Econometric Society, 424-438. https://doi.org/10.2307/1912791

[24] Daubechies, I. (1992) Ten Lectures on Wavelets. SIAM, Philadelphia. https://doi.org/10.1137/1.9781611970104 